\title{
Л.М. Плетнёва
}

\section{БРОНЗОВЫЕ «СКИФСКИЕ» КОТЛЫ ИЗ с. ДЗЕРЖИНСКОЕ (ТОМСКАЯ ОБЛАСТЬ)}

\begin{abstract}
В научный оборот вводятся находки двух бронзовых «скифских» котлов из с. Дзержинское. На основании их формы, расположения ручек, орнаментации делается вывод об их отнесении к минусинскому типу, распространённому далеко за пределами территории тагарской культуры. В Томском Приобье бронзовый котёл происходит с ритуального места, который вместе с другими предметами датируется примерно VI-IV вв. до н.э. Если время употребления котлов из с. Дзержинское не ясно, то благодаря присутствию котла на ритуальном месте сделан вывод об употреблении бронзовых котлов томским населением в эпоху раннего железа.

Ключевые слова: археологическая культура; бронзовые «скифские» котлы; хронология; типология; ритуальное место; скифосибирский мир.
\end{abstract}

Одним из знаковых предметов скифо-сибирского мира является бронзовый котёл. Котлы найдены на всём его пространстве и далеко за его пределами: в лесной зоне Евразии, на Кавказе и Киргизии.

В Западной Сибири котлы происходят с территорий гороховской, саргатской, большереченской (каменской), шеломокской и кулайской культур [1-9]. Котлы встречаются на поселениях ${ }^{2}$, в погребениях ${ }^{3}$, на писаницах ${ }^{4}$, ритуальных местах ${ }^{5}$. Но большинство их происходит не из археологических комплексов, а найдено случайно ${ }^{6}$.

Цель данной статьи - ввести в научный оборот находки скифских котлов из с. Дзержинское Томского района Томской области. Два котла были найдены на усадьбе Д.Ф. Смирнова на глубине 40 см при проведении сельскохозяйственных работ. Впоследствии были переданы в Томский областной краеведческий музей, где хранятся в настоящее время [10. № 1139. С. 104]. Дадим их описание.

1. Бронзовый котёл на поддоне в форме усечённого сфероида с отогнутым наружу краем венчика, который утолщён в нижней части и срезан внутрь. Вертикальные ручки в форме вытянутого овала наполовину возвышаются над краем котла. Первоначально ручки, видимо, были отлиты сразу с корпусом, так как следов прилива на тулове котла в месте отломленной сейчас ручки нет. Вторая ручка, которая сейчас на котле, была отломлена когда-то и прилита, видимо, позже. Ручки украшены двумя желобками. Сверху на них по три грибовидных выступа. Тулово котла украшено тремя рядами валиков. В настоящее время котёл имеет повреждения: отломаны одна ручка и поддон, тулово деформировано, есть трещины и три заплатки. На одной ручке средний выступ одет на ручку с помощью муфты, отлит был, видимо, отдельно, так как на муфте нет орнамента - желобков. На тулове прослеживаются два вертикальных литейных шва, один из которых виден хорошо, второй - частично. Размеры котла: диаметр устья: 18,5-24,5 см (за счёт деформации), высота котла с ручкой 24,7 см, высота ручки от края венчика 11,6 см, высота выступа на ручках 2,15 cм, диаметр шляпки
3 см. Диаметр по внешнему краю конического полого поддона 10,5 см, диаметр в месте крепления к тулову 6,6 см, высота поддона 8,2 см. На поддоне зафиксированы четыре вертикальных валика, два из них имеют продолжение на тулове (рис. 1, 1, 2, ТОКМ, кол. № 3824/11).

2. Бронзовый котёл на коническом поддоне. Целый, но на тулове имеются 10-11 заплаток, наложенных как с внешней, так и внутренней стороны. Край венчика немного отогнут наружу и срезан внутрь. Тулово котла имеет форму усечённого сфероида. В верхней части оно украшено шнуром в виде перевитой верёвочки в два оборота. Шнур заканчивается петлёй. Вертикальные ручки подковообразной формы с одним выступом - отростком посередине. Верх у них отломлен. Размеры котла: диаметр тулова по внешнему краю $21 \mathrm{~cm}$, диаметр поддона по внешнему краю 9,5-10 см, высота котла с ручками 28,5 cм, высота ручек 5,4 см, высота поддона 6,8 см. На тулове котла в нижней части прослеживаются следы горизонтального литейного шва. При соединении тулова котла с поддоном отлиты три клина, видимо, для усиления крепления поддона к тулову (рис. 2, 1, 2; ТОКМ. № 3824/12).

О технологии изготовления котлов. Технология изготовления котлов не так часто попадала в поле исследований учёных [16, 17]. По форме котлов и их деталей выделено несколько районов их основного распространения: Причерноморье, Кавказ, поволжские и приуральские степи, Средняя Азия, Семиречье, Минусинская котловина. В части из них было самостоятельное производство котлов. Одним из таких районов являлась Минусинская котловина. Ю.С. Гришин, описывая производство тагарской культуры в целом, рассматривал технологию производства котлов. Изготовление котлов из с. Дзержинское хорошо прослеживается по способам, описанным Ю.С. Гришиным. Он выделил две группы. При изготовлении формы для котлов первой группы сначала делали тулово, затем часть дна с поддоном и присоединяли к основной форме. Двустворчатые литейные формы для ручек делали отдельно и также присоеди- 
няли к основной форме, что прослеживается по литейным швам на наружной поверхности котла около ручек и на венчике [17. С. 169-170]. На внешней стороне тулова котла, отлитого по описанной форме, есть горизонтальный шов, располагающийся внизу тулова. Внутри котла швы прослеживаются очень редко 7

Ко второй группе относятся котлы, имеющие вертикальный литейный шов снаружи, отлитые иногда вместе с поддоном. Он делит котёл на две симметричные части. В месте соединения тулова и поддона есть горизонтальный литейный шов. Около ручек на тулове котла нет следов литейных швов [Там же. С. 170]. Один котел из с. Дзержинское отлит первым способом (рис. 2), другой - вторым способом (рис. 1).

На многих котлах есть заплаты. Большинство исследователей считают их следами починки в ходе использования котлов. Ю.С. Гришин отмечает, что в процессе отливки могли образоваться пустоты. В этом случае литейщики, чтобы не изготовлять котёл заново (особенно трудоёмким был процесс изготовления формы), приливали заплаты [Там же. С. 171].

Классификация и хронология. Н.Л. Членова разделила бронзовые котлы тагарской культуры на два типа. Тип А - на полом коническом поддоне, тип В - без поддона или на ножках. Тип А делится на две разновидности: А/ I - без носика, A/II и A/III - с носиком.

A/I - ручки бывают кольцевидные, подковообразные или в виде фигурок стоящих животных.

Далее ей выделены группы: группа А I/1 с кольчатыми ручками, нижняя половина их укреплена на тулове, украшены 1-2 концентрическими желобками или одним или тремя грибовидными выступами. Форма тулова полуяйцевидная или близкая к полушару. В верхней части тулово украшено двумя кольцевидными поясками, иногда с косыми насечками, имитирующими шнур [18. С. 93]. Котлы из с. Дзержинское относятся к группе А I/1.

По хронологии котлы с кольцевидными ручками с желобками группы А I/1 отнесены Н.Л. Членовой к наиболее ранним тагарским котлам. Такие котлы появились в VIII - начале VII в. до н.э., но бытовать они могли и позднее [Там же. С. 95]. Котлы с подковообразными ручками с выступами на них появляются в начале VI в. до н.э. Котлы из с. Дзержинское датируются, видимо, раннетагарским временем (по времени их появления, но не употребления).

В статье Н.А. Боковенко [19] приведена типология бронзовых котлов в азиатских степях, данные объединены в рис. 1. К сожалению, этим рисунком трудно воспользоваться, так как не дана расшифровка аббревиатуры музеев: например, ТКМ, что это - Томский краеведческий музей, или Тобольский краеведческий музей, или Тюменский краеведческий музей? Из всех котлов, обозначенные как хранящиеся в ТКМ (а их 5 экз.), можно соотнести с Томским краеведческим музеем только номера 26 и 27, обозначенных как д. Степа- новка. Речь, видимо, идёт о колоколовидной подвеске из Степановской коллекции, собранной у пос. Степановка в пределах г. Томска. Но в коллекции только одна подвеска и котлов нет.

Условно котёл из с. Дзержинское (рис. 1) по типологии Н.А. Боковенко можно отнести к типу I, подтипу С. Второй котёл (рис. 2) относится также к типу I, подтипу Д ${ }^{8}$. Н.А. Боковенко не согласен с хронологией котлов минусинского типа, предложенной Н.Л. Членовой, на том основании, что котлы с разным оформлением ручек встречаются на писаницах. Следовательно, по его мнению, в момент нанесения их на писаницы они сосуществовали [19. С. 46-47]. Котлы I типа с разными типами ручек (у Н.Л. Членовой именно по этому признаку дана хронология) он датирует временем появления их в VIII-VII вв. до н.э., а возможно и раньше, и временем прекращения их изготовления из бронзы. В целом Н.А. Боковенко заключает: «Пока ещё котлы не могут служить датирующим материалом, и поэтому устанавливать их абсолютную хронологию рано» [Там же. С. 49].

Котёл из с. Дзержинское, описанный под № 1 по хронологии Н.Л. Членовой отнесён нами по дате появления таких котлов к VIII-VII вв. По технологии изготовления он относится ко II типу (по Ю.С. Гришину), наиболее трудоёмкому, как отмечает Ю.С. Гришин, и, возможно, появившемуся позднее. Если это так, то этот котёл мог быть изготовлен в более позднее время, чем VIII-VII вв. до н.э. Котёл № 2 изготовлен менее трудоёмким способом, но по форме ручек он отнесён к более позднему времени. Данный факт (если придерживаться хронологии Н.Л. Членовой) может говорить о длительности изготовления котлов с ручками, украшенными желобками, что, соответственно, не противоречит позиции Н.А. Боковенко.

На котле, украшенном двумя рядами перевитой верёвочки (рис. 2, 1), нижний ряд верёвочки заканчивается петлёй. На бронзовых котлах такая деталь встречается довольно редко. Как пример можно назвать котёл из МАЭС ТГУ. Он очень большой: диаметр устья 38 см, высота без ручек 42 см, с ручками 49 см, высота поддона 7 см. Орнаментирован двумя рядами верёвочки, нижняя из них заканчивается петлёй. Котёл происходит из Минусинского округа, найден близ дер. Табатской 9 . Нами найден рисунок глиняного сосуда, у которого к нижнему ряду шнура примыкает петля [21. Рис. 4, 3]. Сосуд происходит из таштыкского могильника Барсучиха II. Л.Л. Баркова приводит мнение Л.Р. Кызласова о том, что спиральный орнамент не характерен для тагарской культуры, в таштыкской культуре он был только на её первом тапе [Там же. С. 172]. Автор этой статьи не склонен ставить знак равенства между петлёй на бронзовом котле и спиралькой на глиняном сосуде, но, возможно, это указывает на более позднее изготовление котла из с. Дзержинское, чем в раннетагарское время. 

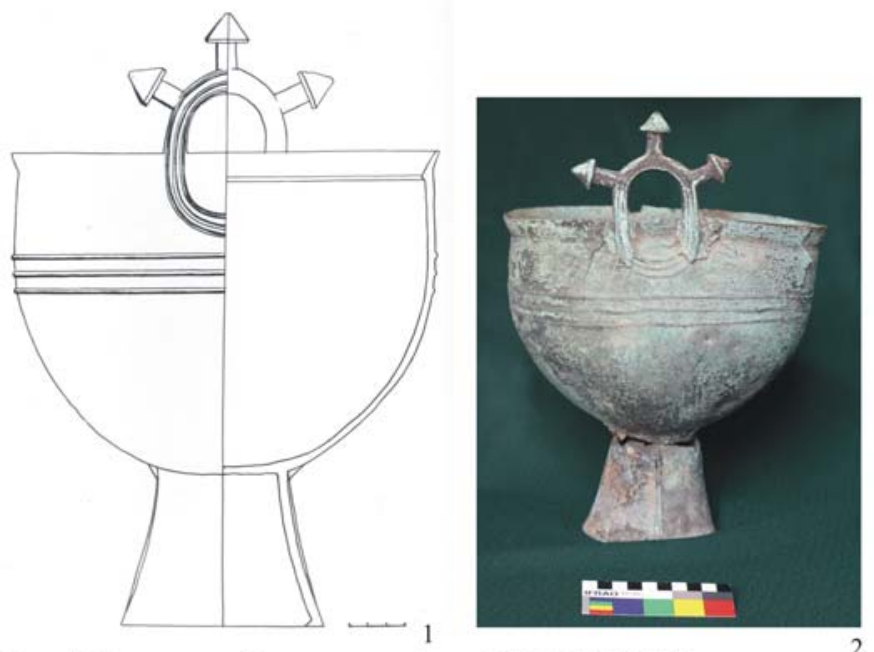

Рис. 1. Котел из пос. Дзержинского (колл. ТОКМ № 3824/11)
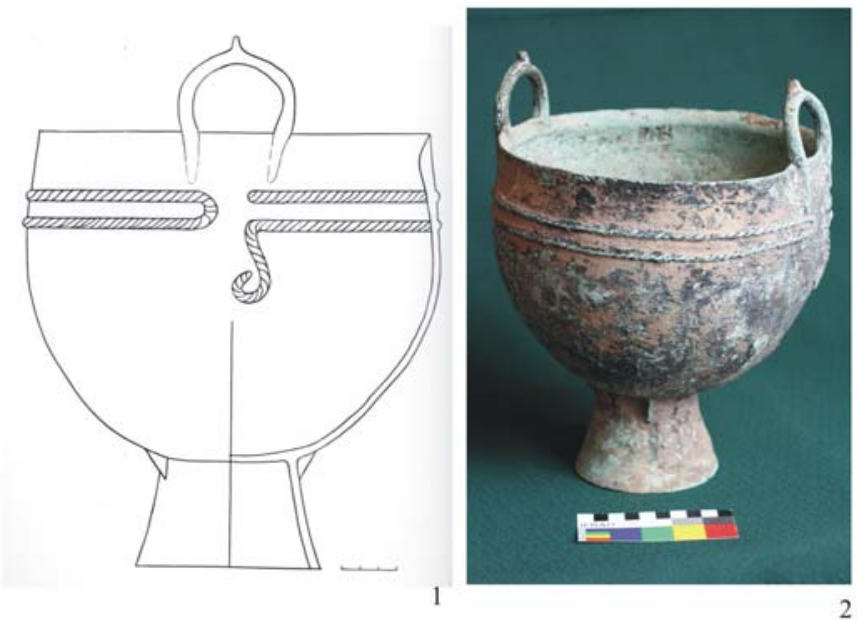

Рис. 2. Котел из пос. Дзержинского (колл. ТОКМ № 3824/12)

Оба котла были найдены вместе, в котле с овальной ручкой с грибовидными тремя выступами были помещены следующие железные предметы (гарпун, наконечник стрелы, два ножа, тесло; бронзовые предметы: антропоморфная личина, две бронзовые пластинки). В этом случае котлы были использованы вторично, так как железные предметы относятся к Средневековью. Видимо, поэтому в «Археологической карте Томской области» дзержинские находки II вслед за Ю.И. Ожередовым и Я.А. Яковлевым Л.М. Сыркиной атрибутированы как клад, но названы «скифским» кладом, или «скифской» коллекцией, что противоречит датировке предметов, найденных в одном из котлов [10. С. 104]. Определение «скифская», утвердившееся за коллекцией, Л.А. Чиндина считает неудачным. Данные котлы, использовавшиеся чрезвычайно долго в культовых целях, содержали предметы, относящиеся к раннему Средневековью [22. Рис. 12, 24, 8. С. 36].

Таким образом, установить, когда появились описанные котлы в Томском Приобье, не представляется возможным. Но о том, что в эпоху раннего железа население Томского Приобья было знакомо со скиф- скими бронзовыми котлами, говорит находка котла в составе других предметов на ритуальном месте эпохи раннего железа, обнаруженного при раскопках курганного могильника у устья М. Киргизки $[7,9]$.

$O$ назначении котлов. Ю.В. Балакин выделил несколько функций котлов: 1) репродуктивная, 2) связь котла с идеей плодородия, 3) котёл как транспортное средство, 4) котёл выполняет посреднические функции между людьми и духами, 5) котёл - заменитель шаманского бубна у некоторых народов (нганасаны, ханты), 6) котёл участвует в установлении связи между мирами, 7) космический статус котла (ханты называют созвездие Большой медведицы котлом), 8) охранительные, защитные функции [23. С. 198-208].

Для нашей статьи следует обратить внимание на связь котла с идеей плодородия, благополучия. Если мы обратимся к котлу, найденному на ритуальном месте у устья М. Киргизки, где он выполнял главную функцию в ритуале, то высказанная ранее авторами публикации мысль о том, что ритуалы, проводимые здесь, связаны с испрашением благополучия для данного коллектива, подтверждается на многих других примерах. 
Во время ритуалов котёл выполнял посреднические функции между людьми и духами (божествами), осуществляя в этот момент связь между мирами. М.А. Дэвлет, приводя пример использования сосудов на якутских праздниках «ысыах» (весеннем и осеннем), которые были связаны с идеей плодородия, отмечала: «Нельзя настаивать на прямых параллелях с наскальными рисунками и данными этнографии. Всё же есть основания полагать, что на Большой Боярской писанице представлен ирреальный, идеальный посёлок в момент традиционного календарного праздника. Древние художники... ставили себе целью обеспечить при помощи этих рисунков материальное благополучие, изобилие и процветание реального населения» [12. C. 11].

Исходя из расположения котлов на писанице, не опровергая мнение М.А. Дэвлет, попробуем определить как один из вариантов трактовки функций котлов их защитную функцию. Так, на части Большой Боярской писаницы изображён посёлок в два ряда [Там же. Табл. $\mathrm{VI}, 1]$. В верхнем ряду слева изображены пять скифских котлов, затем идут постройки, животные, человек с луком и копьём, постройка и животные. Во втором ряду выбиты постройки, животные, всадник, человек (?) между ними и рядами, заканчивается ряд изображением трёх котлов. Один котёл помещен между первым и вторым рядом изображений. В нижнем, третьем, ряду слева направо движутся животные и всадники. Котлы как бы огораживают посёлок, защищая его.

Об использовании котлов в похоронных ритуалах свидетельствуют котлы, найденные в могильнике Си- доровки. Так, в кургане 1 , могиле 2 , «большой котёл был накрыт шкурой коровы или лошади. Внутри котла обнаружены кости лошади (крестец, грудина, часть лопатки) и коленная чашечка особи крупного рогатого скота» [5. С. 11]. В кургане 5, могиле 1, по мнению авторов: «Вероятно, котёл был поставлен на возвышении с имитированным костром» (под котлом найдены три полена длиной 15 см) [Там же. С. 28]. В кургане 7, погребении 2 Савинского могильника, в котле были остатки черепа молодой лошади [3. С. 36]. Возможно, наличие в котлах костей животных также указывает на связь миров (подношения из Среднего мира в Верхний или Нижний миры).

Котлы из погребений определяют социальный статус погребённого: чаще всего это погребения знати [24].

Исходя из вышеизложенного, можно сделать следующие выводы:

1. Бронзовые «скифские» котлы из пос. Дзержинское по форме тулова, поддона и ручек относятся к котлам Минусинского типа.

2. Время попадания котлов из пос. Дзержинское в Томское Приобье определить невозможно.

3. Население Томского Приобья в эпоху раннего железа пользовалось бронзовыми котлами, о чём свидетельствуют котёл, найденный на ритуальном месте, а также бронзовая подвеска в форме котла из Степановской коллекции.

4. По своему назначению котлы являются символом единения какого-то коллектива, с их помощью обращались к богам, испрашивая благополучия, защиты и здоровья.

\section{ПРИМЕЧАНИЯ}

\footnotetext{
${ }^{1}$ В статье привлечены в основном западно- и южносибирские материалы.

${ }^{2}$ Например, поселения в Томской области: Заречная Горка и Красногоркинское [10. № 1009, 1012], в Кемеровской области поселение Шабаново VI [11]

${ }^{3}$ Например, в Западной Сибири: в могильниках Богдановка I, II, III, Савинском, Красногорском, Сидоровка [4. С. 302].

${ }^{4}$ Большая Боярская писаница [12].

${ }^{5}$ Ритуальный комплекс эпохи раннего железа на Малой Киргизке [7].

${ }^{6}$ Мною просмотрена коллекция котлов в Музее археологии и этнографии Сибири ТГУ (МАЭС ТГУ), состоящая из 20 единиц хранения (целые и фрагменты). Только один из них найден на ритуальном месте, отмеченном выше. Коллекция котлов из Томского областного краеведческого музея насчитывает пять целых и фрагменты ещё от пяти котлов. Все котлы, за исключением одной подвески в форме котла и фрагментов котла с ритуального места у горы Кулайка (Томская область), найдены случайно. Из опубликованных 26 котлов и их фрагментов, хранящихся в Центральном музее Казахстана, все - случайные находки [13]. Большинство их ранее было опубликовано Е.Ю. Спасской [14], Ф.Х. Арслановой, А.А. Чариковым [15] и другими авторами.

${ }^{7}$ Нами обнаружен такой котёл в МАЭС ТГУ, кол. 6272, № 801.

${ }^{8}$ Варианты не определены, так как даны в рис. 1 далеко не все, и установить их для котлов из с. Дзержинское затруднительно.

9 Флоринский В.М. Второе прибавление к каталогу Археологического музея Томского университета, № 4691 [20]. Под этим номером он значится и в настоящее время, выставлен в экспозиции МАЭС ТГУ.
}

\section{ЛИТЕРАТУРА}

1. Мошинская В.И. Городище и курганы Потчеваш // Материалы и исследования по археологии СССР. 1953. Вып. 35. С. $189-220$.

2. Корякова Л.Н. Ранний железный век Зауралья и Западной Сибири (саргатская культура). Свердловск, 1988.240 с.

3. Матвеева Н.П. Саргатская культура на Среднем Тоболе. Новосибирск : Наука, 1993. 173 с.

4. Могильников В.А. Ранний железный век лесостепи Западной Сибири // Степная полоса Азиатской части СССР в скифо-сарматское время: Археология СССР. М. : Наука, 1992. С. 274-283.

5. Матющенко В.И., Татаурова Л.В. Могильник Сидоровка в Омском Прииртышье. Новосибирск : Наука, Сиб. предприятие РАН, 1997.198 с.

6. Троицкая Т.Н., Бородовский А.П. Большереченская культура лесостепного Приобья. Новосибирск : Наука, 1994.184 с.

7. Плетнева Л.М., Мец Ф.И. Ритуальный комплекс эпохи раннего железа в Томском Приобье // Приобье глазами археологов и этнографов. Томск : Изд-во Том. ун-та, 1999. С. 145.

8. Мец Ф.И. «Скифский» котёл с зооморфными ручками из Томского Приобья // Российская археология. 2000. № 4. С. 128-136.

9. Плетнева Л.М. Предметы скифо-сибирского звериного стиля из Томского Приобья. Томск : Изд-во Том. гос. пед. ун-та, 2012.190 с.

10. Ожередов Ю.И., Яковлев Я.А. Археологическая карта Томской области. Томск : Изд-во Том. ун-та, 1993. Т. II. 208 с. 
11. Илюшин А.М., Ковалевский С.А. Итоги исследования древностей раннего железного века Кузнецкой комплексной археологоэтнографической экспедиции // Итоги изучения скифской эпохи Алтая и сопредельных территорий. Барнаул : Изд-во Алт. гос. ун-та, 1999. С. $60-64$.

12. Дэвлет М.А. Большая Боярская писаница. М. : Наука, 1976. 20 с.

13. Культура ранних кочевников Казахстана: археологические коллекции. Научный каталог. Алматы, 2009.430 с.

14. Спасская Е.Ю. Медные котлы ранних кочевников Казахстана и Киргизии // Учёные записки Алматинского гос. пед. ин-та им. Абая. АлмаАта, 1956. T. XI (I). C. 155-169.

15. Арсланова Ф.Х., Чариков А.А. Бронзовые котлы из музеев Восточно-Казахстанской области // Скифо-сибирское культурно-историческое единство. Кемерово : Кем. гос. ун-т, 1980. С. 147-155.

16. Гришин Ю.С. Производство в тагарскую эпоху // Материалы и исследования по археологии СССР. 1960. Вып. 90. С. 167-172.

17. Минасян Р.С. Литьё бронзовых котлов у народов степей Евразии (VII в. до н.э. - V в. н.э.) // «Археологический сборник» Государственного Эрмитажа. 1986. № 27. 208 c.

18. Членова Н.Л. Происхождение и ранняя история племён тагарской культуры. М. : Наука, 1967. С. 67-78.

19. Боковенко Н.А. Бронзовые котлы ранних кочевников в азиатских степях // Проблемы западносибирской археологии. Эпоха железа. Новосибирск : Наука, 1981. С. 42-52.

20. Флоринский В.М. Второе прибавление к каталогу Археологического музея Томского университета. Томск, 1898.173 с.

21. Баркова Л.Л. Таштыкский могильник Барсучиха II // Первобытная археология Сибири. Л. : Наука, 1975. С. $165-173$.

22. Чиндина Л.А. История Среднего Приобья в эпоху Раннего Средневековья. Томск : Изд-во ТГУ, 1991.184 с.

23. Балакин Ю.В. Урало-сибирское культовое литьё в мифе и ритуале. Новосибирск : Наука. Сиб. предприятие РАН, 1998. 288 с.

24. Кузнецова Т.М. О подвеске «в форме котла» из кургана Аржан-2 // Культуры степной Евразии и их взаимодействие с древними цивилизациями. СПб. : ИИМК РАН, Периферия, 2012. Кн. 1. С. 258-261.

\section{Pletneva Lyudmila M. Tomsk State Pedagogical University (Tomsk, Russia). E-mail: tspu kae@mail.ru}

\section{BRONZE "SCYTHIAN" CAULDRONS FROM THE VILLAGE OF DZERZHINSKOYE (TOMSK REGION).}

Keywords: archaeological culture; bronze "Scythian" cauldrons; chronology; typology; ritual place; Scythian-Siberian world.

Bronze cauldrons are one of the most significant artifacts of the Scythian-Siberian world. In Western Siberia, they are known in the areas of Gorokhovo, Sargat, Bolsherechye (Kamenka), and Kulay cultures. They were found in settlements, burial and ritual sites. However, most of them were found by chance. Two cauldrons were found in a garden in the village of Dzerzhinskoye. The aim of this article is to introduce these findings into scientific use. Both cauldrons are on a conical tray, with vertical handles, with ornaments on their bodies: three rows of rollers on one of them and two rows of a twisted cord ending with a loop on the other one. One of the cauldrons has a horizontal casting seam, the other one - a vertical seam. The described features suggest that both cauldrons are of the Minusinsk type and were cast within the Tagar culture. These cauldrons were found together. Inside the cauldron with an oval handle were several iron items: an arrow head, two knives, a share, and adze. There also were three bronze items: anthropomorphous image and two plates. Both iron and bronze things belong to the Middle Ages. The cauldrons were used a second time. The time when they were delivered to the Tomsk Ob Region is unknown, mainly due to the fact that one of the cauldrons contained some iron objects dated back to the Middle Ages. The fact that the population of the Tomsk Ob Region used bronze cauldrons is supported by the finding from a ritual site at the mouth of the Malaya Kirgizka River. Here, the cauldron was the key object for ritual actions. Researchers made several assumptions about the purpose of cauldrons in the early Iron Age. We believe that Yu. V. Balakin has provided the most complete answer to this question. With regard to the early Iron Age, the following functions of bronze cauldrons can be noted: they often determine the social status (when found in burial sites), are associated with the idea of fertility, act as a mediator in ritual actions, act as a link between humans and spirits, help to establish links between the worlds, have the cosmic status and protective functions.

\section{REFERENCES}

1. Moshinskaya, V.I. (1953) Gorodishche i kurgany Potchevash [The site of ancient settlement and mounds Potchevash]. Materialy $i$ issledovaniya po arkheologii SSSR. 35. pp. 189-220.

2. Koryakova, L.N. (1988) Ranniy zheleznyy vek Zaural'ya i Zapadnoy Sibiri (sargatskaya kul'tura) [The Early Iron Age of Trans-Urals and Western Siberia (the Sargat culture)]. Sverdlovsk: Ural State University.

3. Matveeva, N.P. (1993) Sargatskaya kul'tura na Srednem Tobole [The Sargat culture in the Middle Tobol]. Novosibirsk: Nauka.

4. Mogilnikov, V.A. (1992) Ranniy zheleznyy vek lesostepi Zapadnoy Sibiri [The Early Iron Age of the Western Siberian firest-steppe]. In: Rybakov, B.A. (ed.) Stepnaya polosa Aziatskoy chasti SSSR $v$ skifo-sarmatskoe vremya [The steppe zone of the Asian part of the USSR in the ScythianSarmatian time]. Moscow: Nauka. pp. 274-283.

5. Matyushchenko, V.I. \& Tataurova, L.V. (1997) Mogil'nik Sidorovka v Omskom Priirtysh'e [The burial Sidorovka in the Omsk Irtysh]. Novosibirsk: Nauka.

6. Troitskaya, T.N. \& Borodovskiy, A.P. (1994) Bol'sherechenskaya kul'tura lesostepnogo Priob'ya [The Bolsherechye culture of the forest-steppe Ob]. Novosibirsk: Nauka

7. Pletneva, L.M. \& Mets, F.I. (1999) Ritual'nyy kompleks epokhi rannego zheleza v Tomskom Priob'e [The ritual complex of the Early Iron Age in the Tomsk Ob Area]. In: Chernyak, E.I. (ed.) Priob'e glazami arkheologov $i$ etnografov [The Ob Area as viewed by archeologists and ethnographists]. Tomsk: Tomsk State University. p. 145.

8. Mets, F.I. (2000) The "Scythian" cauldron with zoomorphic handles from the Ob basin near Tomsk. Rossiyskaya arkheologiya - Russian Archeology. 4. pp. 128-136. (In Russian).

9. Pletneva, L.M. (2012) Predmety skifo-sibirskogo zverinogo stilya iz Tomskogo Priob'ya [Objects of Scytho-Siberian zoomorphic style art from the Ob basin near Tomsk]. Tomsk: Tomsk State Pedagogical University.

10. Ozheredov, Yu.I. \& Yakovlev, Ya.A. (1993) Arkheologicheskaya karta Tomskoy oblasti [The archaeological map of Tomsk Region]. Vol. 2. Tomsk: Tomsk State University.

11. Ilyushin, A.M. \& Kovalevskiy, S.A. (1999) Itogi issledovaniya drevnostey rannego zheleznogo veka Kuznetskoy kompleksnoy arkheologoetnograficheskoy ekspeditsiey [The results of the study of the Early Iron Age antiquities by Kuznetsk complex archaeological and ethnographic expedition]. In: Kiryushin, Yu.F. \& Tishkin, A.A. (eds) Itogi izucheniya skifskoy epokhi Altaya i sopredel'nykh territoriy [The results of the study of the Scythian period in Altai and adjacent territories]. Barnaul: Altai State University. pp. 60-64.

12. Devlet, M.A. (1976) Bol'shaya Boyarskaya pisanitsa [Petroglyphs at Boyary mountain range]. Moscow: Nauka.

13. Kul'tura rannikh kochevnikov Kazakhstana: arkheologicheskie kollektsii [The culture of the early nomads of Kazakhstan: archaeological collections]. (2009) Almaty: TsGM RK. 
14. Spasskaya, E.Yu. (1956) Mednye kotly rannikh kochevnikov Kazakhstana i Kirgizii [The copper cauldrons of the early nomads in Kazakhstan and Kyrgyzstan]. Uchenye zapiski Almatinskogo gos. ped. in-ta im. Abaya. 9(1). pp. 155-169.

15. Arslanova, F.Kh. \& Charikov, A.A. (1980) [Bronze pots from the museums of the East Kazakhstan]. Skifo-sibirskoe kul'turno-istoricheskoe edinstvo [The Scythian-Siberian cultural and historical unity]. Proc. of the 1st All-Russian Archeological Conference. Kemerovo: Kemerovo State University. pp. 147-155. (In Russian).

16. Grishin, Yu.S. (1960) Proizvodstvo v tagarskuyu epokhu [Manufacture in Tagar era]. Materialy i issledovaniya po arkheologii SSSR. 90. pp. 167-172.

17. Minasyan, R.S. (1986) Lit'e bronzovykh kotlov u narodov stepey Evrazii (VII v. do n.e. - V v. n.e.) [Bronze cauldron casting among the peoples of the Eurasian steppes (the 7th century BC - the 5th century AD)]. Arkheologicheskiy sbornik Gosudarstvennogo Ermitazha. 27.

18. Chlenova, N.L. (1967) Proiskhozhdenie i rannyaya istoriya plemen tagarskoy kul'tury [The origin and early history of the Tagar tribes]. Moscow: Nauka.

19. Bokovenko, N.A. (1981) Bronzovye kotly rannikh kochevnikov v aziatskikh stepyakh [Bronze cauldrons of the early nomads in Asian steppes]. In: Troitskaya, T.N. (ed.) Problemy zapadnosibirskoy arkheologii. Epokha zheleza [Problems of the West Siberian archeology. The Iron Age]. Novosibirsk: Nauka. pp. 42-52.

20. Florinskiy, V.M. (1898) Vtoroe pribavlenie k katalogu Arkheologicheskogo muzeya Tomskogo universiteta [The second addition to the catalog of the Tomsk University Archaeological Museum]. Tomsk: P.I. Makushin.

21. Barkova, L.L. (1975) Tashtykskiy mogil'nik Barsuchikha II [The Tashtyk burial Barsuchiha II]. In: Mandelstam, A.M. (ed.) Pervobytnaya arkheologiya Sibiri [The prehistoric archeology of Siberia]. Leningrad: Nauka. pp. 165-173.

22. Chindina, L.A. (1991) Istoriya Srednego Priob'ya v epokhu rannego srednevekov'ya [The history of the Middle Ob in the early Middle Ages]. Tomsk: Tomsk State University.

23. Balakin, Yu.V. (1998) Uralo-sibirskoe kul'tovoe lit'e v mife i rituale [Ural-Siberian cult casting in the myth and ritual]. Novosibirsk: Nauka.

24. Kuznetsova, T.M. (2012) O podveske "v forme kotla" iz kurgana Arzhan-2 [About the pendant "in the form of the cauldron" from Arzhan-2]. In: Alekshin, V.A. et al. (eds) Kul'tury stepnoy Evrazii $i$ ikh vzaimodeystvie s drevnimi tsivilizatsiyami [Cultures of the Eurasian steppe and their interaction with the ancient civilizations]. St. Petersburg: Institute of Material Culture History RAS, Periferiya. pp. $258-261$. 